\title{
Ceftraixone induced anaphylaxis and death: a case report
}

\author{
Ameya Puranik* \\ Department of Pharmacology, JNMC, Sawangi, Wardha, Maharashtra, India \\ Received: 23 December 2020 \\ Accepted: 02 March 2021 \\ *Correspondence: \\ Dr. Ameya Puranik, \\ Email: ameypuranik1@gmail.com \\ Copyright: (C) the author(s), publisher and licensee Medip Academy. This is an open-access article distributed under \\ the terms of the Creative Commons Attribution Non-Commercial License, which permits unrestricted non-commercial \\ use, distribution, and reproduction in any medium, provided the original work is properly cited.
}

\begin{abstract}
Ceftriaxone, a broad spectrum third generation cephalosporin antibiotic and sulbactam is a beta-lactamase inhibitor. The combination is used for pre-operative surgical prophylaxis for prevention is secondary bacterial infection. We describe a patient who developed anaphylaxis and death soon after intravenous administration of ceftriaxone and sulbactam combination and review similar cases of adverse effects to these class of drugs. The patient was a 68 year old male admitted to surgery ward for obstructed inguinal hernia. He was prescribed injection ceftriaxone and sulbactam combination along with concomitant medication injection pantoprazole and injection metronidazole. The patient was injected injection ceftriaxone and sulbactam, within 15 minutes he suddenly developed anaphylactic shock and died for fluid aspiration in lungs during resuscitation. PubMed was searched for the following terms: anaphylaxis, ceftriaxone, sulbactam. The papers containing these terms and their references were reviewed. Anaphylactic shock caused by ceftriaxone is an uncommon adverse event in patients receiving the drug. However, similar reactions have been observed in some cases in India and world-wide. Clinicians should be aware that anaphylaxis secondary to ceftriaxone and sulbactam combination is a serious death threatening side-effect.
\end{abstract}

Keywords: Ceftriaxone, Anaphylaxis, Death, Drug safety, Pharmacovigilance, ADR, SUSAR

\section{INTRODUCTION}

Third generation cephalosporins are bactericidal broad spectrum beta-lactam antibiotics active mainly against gram negative bacteria. Ceftriaxone has shown high efficacy in a wide range of serious infections including bacterial meningitis (especially in children), multi-drug resistant typhoid fever, complicated urinary tract infections, abdominal sepsis and septicaemias. ${ }^{1}$ Ceftriaxone has also shown to be effective in post-surgical prophylaxis against opportunistic infections. ${ }^{2}$

\section{CASE REPORT}

This is a case of 68 year old male patient. The patient was a known case of right sided inguinal hernia inguinal hernia since six months, and was not any medical treatment. He suddenly came to emergency department in night with severe pain in right loin. He was clinically examined and diagnosed of obstructed inguinal hernia. He was given symptomatic analgesic in emergency department and admitted to surgery ward for pre-operative preparation after patient became stable.

The patient was posted for surgery in the morning, and was prescribed injection ceftriaxone and sulbactam, injection metronidazole and injection pantoprazole all drugs to be given intravenously in comfortable interval with flushing I.V. cannula in between the administration of various drugs, for surgical prophylaxis of bacterial infections. Firstly, the patient was administered injection ceftriaxone and sulbactam. Within 15 minutes of administration, the patient started difficulty in breathing. The resident doctor present in the department was called immediately by ward nurse, the resident after examining the patient noticed that his pulse is feeble, blood pressure and oxygen saturation $\left(\mathrm{SpO}_{2}\right)$ is falling rapidly. The resident doctor immediately injected injection adrenaline 1:100000 IU and patient was 
prepared for resuscitation. The patient was cardiopulmonary resuscitation (CPR) for approximately 30 minutes, after which no pulse found, hence the patient declared dead due to anaphylactic shock.

The in-charge doctor contacted the regional pharmacovigilance centre and notified the adverse reaction occurred. The adverse reaction was reported to pharmacovigilance program of India (PvPI) through vigiflow under case safety report Id: 2017-05379 at regional adverse drug reaction monitoring centre, Sawangi (Meghe), Wardha (M.S.).

\section{DISCUSSION}

In this case, we have suspected ceftriaxone, a $3^{\text {rd }}$ generation cephalosporin to be causative agent for this reaction. $3^{\text {rd }}$ generation cephalosporins are broad spectrum beta-lactam antibiotics which also include cefotaxime, cefixime, cefoperazone and several others. They were first introduced into market in 1980s. Third generation of cephalosporins are active against gram negative bacteria and resistant to their beta-lactamases. ${ }^{3}$ Ceftriaxone distinguishingly has longer duration of action, compared to several other antibiotics and it is also active against hospital acquired infection caused by pseudomonas. ${ }^{4}$ It is regularly used for surgical prophylaxis against opportunistic infections. $^{2}$

Common adverse drug reactions of cephalosporins are pain at injection site, diarrhoea, neutropenia, thrombocytopenia, hypoprothrombinaemia, nephrotoxicity and hypersensitivity reactions. Amongst all these adverse effects, hypersensitivity reactions are most important, manifestations observed are similar to penicillin, but incidence is much lower. Common manifestations are, rashes, urticarial, angioedema and anaphylaxis in rare cases. Intradermal skin test is very unreliable, penicillin's should be totally avoided in patients with history of allergy to penicillin and other betalactam group of antibiotics. 5

In our patient, the vitals are completely stable before administration of intravenous injection of ceftriaxone and sulbactam, there is no any other explanation for the such severe anaphylactic reaction caused to him, other medications i.e. injection metronidazole and injection pantoprazole are certainly not responsible for above mentioned reactions, as no documented case ID available in the history of metronidazole and pantoprazole given by intravenous route. The WHO scale grading of above adverse reaction was considered certain and according to (Harwig and Seigel) scale it falls under severe category.

Some recent cases of similar reactions after injection ceftriaxone are described in following Table 1.
Table 1: Recent cases of reactions after injection ceftriaxone.

\begin{tabular}{|l|lrl|}
\hline Sr. no. & $\begin{array}{l}\text { Patient } \\
\text { demographics }\end{array}$ & Year & Author \\
\hline $\mathbf{1}$ & 31 year old female & 2017 & Imam et al \\
\hline $\mathbf{2}$ & 36 year old male & 2016 & Badar et al \\
\hline $\mathbf{3}$ & 22 year old male & 2015 & Kumari et al \\
\hline $\mathbf{4}$ & 9 year old male & 2013 & Shrestha et al \\
\hline $\mathbf{5}$ & 36 year old female & 2011 & Sun et al \\
\hline
\end{tabular}

\section{CONCLUSION}

$3^{\text {rd }}$ generation cephalosporins are been associated with severe adverse reactions in recent past in India. Detailed analysis and review are required nationwide and up gradation of guidelines and hospital based antibiotic policy is required to promote rational use of antibiotics, as resistance to antibiotics and adverse reactions are increasing. Intradermal skin test before administration of cephalosporin even though found out to be inconclusive, should be included in standard procedure for administration of cephalosporins. All adverse reactions should be reported to National pharmacovigilance centre (IPC Ghaziabad).

Funding: No funding sources Conflict of interest: None declared

Ethical approval: Not required

\section{REFERENCES}

1. Tripathi KD. Essentials of Medical Pharmacology. 7th ed. Jaypee. 2013;727.

2. Chalkiadakis GE, Gonnianakis C, Tsatsakis A, Tsakalof A, Michalodimitrakis M. Preincisional single-dose ceftriaxone for the prophylaxis of surgical wound infection. Am J Surg. 1995;170(4):353-5.

3. Sader H. Historical overview of the cephalosporin spectrum: Four generations of structural evolution. Antimicrobic Newsletter. 1992;8(12):75-82.

4. Centers for Disease Control and Prevention (CDC). Update to CDC's Sexually transmitted diseases treatment guidelines, 2010: oral cephalosporins no longer a recommended treatment for gonococcal infections. Morb Mortal Wkly Rep. 2012;61(31):5904.

5. Kelkar PS, Li JT. Cephalosporin allergy. N Engl J Med. 2001;345(11):804-9.

Cite this article as: Puranik A. Ceftraixone induced anaphylaxis and death: a case report. Int J Basic Clin Pharmacol 2021;10:442-3. 